\title{
Is artificial intelligence a superior diagnostician in ulcerative colitis?
}

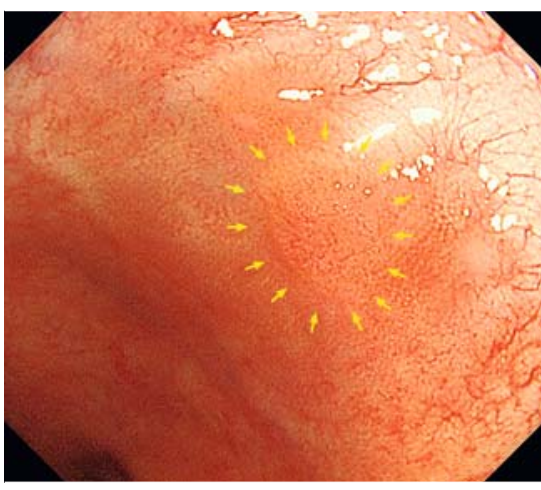

- Fig. 1 Colonoscopic image revealing a slightly elevated reddish lesion in the lower rectum (yellow arrows).

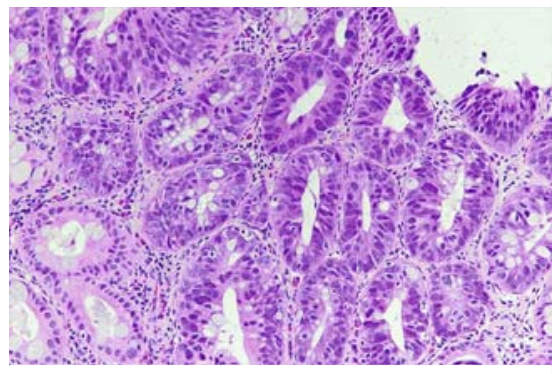

- Fig. 2 Histologic appearance showing an atypical tubular gland with high grade dysplasia in the mucosa.

A 46-year-old woman with a 26-year history of pancolitis visited our hospital regularly. She had remained in remission for the past 5 years and was taking oral mesalamine. Annual endoscopy examination showed a slightly elevated reddish lesion $(5 \mathrm{~mm})$ in the lower rectum ( $\mathbf{F i g} .1$ ). Endocytoscopy (CF-H290ECl; Olympus, Tokyo, Japan) with narrow-band imaging revealed surface microvessels of uniform caliber and arrangement ( $\downarrow$ Video 1 ). An artificial intelligence-based system (EndoBRAIN; Cybernet Systems, Tokyo, Japan) diagnosed the lesion as a neoplasm. On the basis of biopsy findings, we diagnosed the lesion as being high grade dysplasia ( $\mathbf{F i g . 2}$ ) and performed

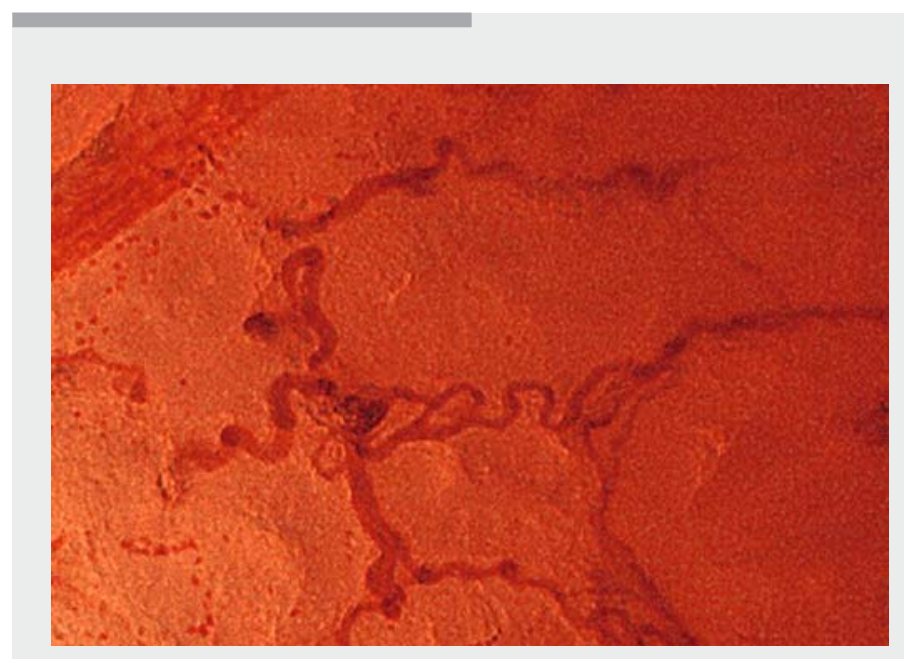

Video 1 View during endocytoscopy with narrow-band imaging showing surface microvessels of uniform caliber and arrangement, which is subjected to computer diagnosis using a two-class diagnosis (non-neoplastic or neoplastic) with probability.

endoscopic submucosal dissection. After treatment, she was discharged on postoperative day 7 , without any complications.

The risk of developing colorectal cancer (CRC) is significantly elevated in patients with ulcerative colitis. Surveillance colonoscopy is usually performed to identify colitis-associated CRC. Endocytoscopy is a novel type of ultramagnification endoscopy that enables microscopic cellular observation, and evaluation of the endocytoscopic microvasculature has been used for the diagnosis of colorectal lesions [1]. The EndoBRAIN system accurately differentiates neoplastic from nonneoplastic lesions in endocytoscopic narrow-band images, when pathological findings are used as the standard [2]. However, its application in the diagnosis of colitis-associated CRC has not previously been reported. Our findings suggest that endocytoscopy can be used to obtain information regarding the endocytoscopic vascular pattern and that EndoBRAIN can help detect colitis-asso- ciated CRC. Furthermore, colitis-associated CRC is often difficult to diagnose because of the effects of inflammation and the use of EndoBRAIN can help nonexpert endoscopists to identify colitisassociated CRC, thereby helping to avoid unnecessary biopsies.

Endoscopy_UCTN_Code_TTT_1AQ_2AB

\section{Competing interests}

The authors declare that they have no conflict of interest.

The authors

Shuhei Fukunaga, Yoshio Kusaba, Akihiro Ohuchi, Tsutomu Nagata, Keiichi Mitsuyama, Osamu Tsuruta, Takuji Torimura

Division of Gastroenterology, Department of Medicine, Kurume University School of

Medicine, Fukuoka, Japan 
Corresponding author

Shuhei Fukunaga, MD

Division of Gastroenterology, Department of Medicine, Kurume University School of Medicine, 67 Asahi-machi, Kurume, Fukuoka 830-0011, Japan

Fax: +81-942-342623

fukunaga_shyuuhei@med.kurume-u.ac.jp

\section{References}

[1] Kudo SE, Misawa M, Wada Y et al. Endocytoscopic microvasculature evaluation is a reliable new diagnostic method for colorectal lesions. Gastrointest Endosc 2015; 82: 912923

[2] Kudo SE, Misawa M, Mori Y et al. Artificial intelligence-assisted system improves endoscopic identification of colorectal neoplasms. Clin Gastroenterol Hepatol 2019. doi:10.1016/j.cgh.2019.09.009

Bibliography

Endoscopy 2021; 53: E75-E76

DOI $10.1055 / \mathrm{a}-1195-1986$

ISSN 0013-726X

published online 26.6.2020

(C) 2020. Thieme. All rights reserved.

Georg Thieme Verlag KG, Rüdigerstraße 14,

70469 Stuttgart, Germany

\section{ENDOSCOPY E-VIDEOS}

https://eref.thieme.de/e-videos

回回 Endoscopy E-Videos is a free access online section, reporting 国: on interesting cases and new techniques in gastroenterological endoscopy. All papers include a high quality video and all contributions are freely accessible online.

This section has its own submission website at

https://mc.manuscriptcentral.com/e-videos 